\title{
Extracellular Biosynthesis of Silver Nanoparticles Using Escherichia coli ATCC 8739, Bacillus subtilis ATCC 6633, and Streptococcus thermophilus ESh1 and Their Antimicrobial Activities
}

\author{
Abd El-Raheem R. El-Shanshoury, ${ }^{1,2}$ Sobhy E. ElSilk, ${ }^{1,3}$ and Mohamed E. Ebeid ${ }^{1}$ \\ ${ }^{1}$ Bacteriology Unit, Botany Department, Faculty of Science, Tanta University, Tanta 31527, Egypt \\ ${ }^{2}$ Biotechnology Department, Faculty of Science, Taif University, P.O. Box 888, Taif 21974, Saudi Arabia \\ ${ }^{3}$ Biological Sciences Department, Faculty of Science and Art, King Abdulaziz University, Rabigh Campus, P.O. Box 344, Rabigh 21911, \\ Saudi Arabia \\ Correspondence should be addressed to Sobhy E. ElSilk, selsilk@yahoo.de
}

Received 26 April 2011; Accepted 2 June 2011

Academic Editors: R. Jin and Y. Joseph

Copyright () 2011 Abd El-Raheem R. El-Shanshoury et al. This is an open access article distributed under the Creative Commons Attribution License, which permits unrestricted use, distribution, and reproduction in any medium, provided the original work is properly cited.

\begin{abstract}
The development of reliable and eco-friendly organisms of silver nanomaterials is an important aspect of current nanotechnology research and application. Recently, microorganisms have been explored as potential biofactory for synthesis of silver nanoparticles. In this study, through screening of common bacteria, we report extracellular biosynthesis of metallic silver nanoparticles by the reduction of aqueous $\mathrm{Ag}^{+}$using Escherichia coli ATCC 8739, Bacillus subtilis ATCC 6633, and Streptococcus thermophilus ESh1 as potential candidates for the rapid synthesis of silver nanoparticles. The culture supernatant of silver nanoparticles biosynthesis by reduction of silver ion coming in contact with the cell filtrate was fast and was formed within few minutes. UV-visible spectrum of the aqueous media obtained from the above bacteria containing silver ion showed a peak around $420 \mathrm{~nm}$ corresponding to the plasmon absorbance of silver nanoparticles. Transmission electron microscopy (TEM) micrographs showed formation of well-dispersed silver nanoparticles in the range of $5-25 \mathrm{~nm}$. X-ray diffraction (XRD) of silver nanoparticles exhibited $2 \theta$ values corresponding to the silver nanocrystal. In vitro studies indicated that the formed silver nanoparticles showed variable antimicrobial activity against Escherichia coli, Bacillus subtilis, Salmonella typhimurium, Klebsiella pneumoniae, Staphylococcus aureus, and Pseudomonas aeruginosa and the fungus like yeast (Candida albicans). The diameter of inhibition zone varied according to the silver nanocrystal concentration and the test microorganism.
\end{abstract}

\section{Introduction}

The synthesis of nanoparticles of different chemical compositions, sizes, and controlled monodispersity is an important area of research in nanotechnology. Nanoparticle shape control is a recent demand being made by newly emerging synthesis methods. In addition, there is a growing need to develop environmentally benign nanoparticle synthesis processes that do not use toxic chemicals in the synthesis protocols. In modern nanoscience, the interaction between inorganic molecules and biological synthesis is one of the most exciting areas of research. In this respect, many unicellular and multicellular microorganisms were viewed as ecofriendly nanofactories to produce inorganic materials either on intraor extracellular level [1-6]. There are several reports in the literature on the cell-associated biosynthesis of silver nanoparticles using several microorganisms. The cell mass of bacteria has been reported to reduce silver ion to silver nanoparticles [7-9].

The development of biologically experimental processes for the synthesis of nanoparticles is evolving into an important branch of nanotechnology [10, 11]. Biologically synthesized silver nanoparticles could have many applications, for example, they might be used as spectrally selective coatings for solar energy absorption and intercalation material for electrical batteries, as optical receptors, as catalysts 
in chemical reactions, for biolabeling, and as sensors, antimicrobial agents, and filters [12-15]. Microorganisms can survive and grow in polluted environments, including water and soil, due to their ability to resist the metal stress. Among the mechanisms in that respect is the alteration of solubility and toxicity via reduction or oxidation $[16,17]$. The present study includes kinetics of synthesis, spectroscopic, and microscopic characterization of the biosynthesis of silver nanoparticles that compete with chemical procedures for nanoparticle synthesis [11]. Considering the growing technological demand for eco-friendly and development of reliable process for the synthesis of silver nanoparticles, the present work was undertaken. The aim of this study is to select the potential candidates for extracellular biosynthesis of silver nanoparticles where the preliminary data (under publication) indicated that Escherichia coli at $(430 \mathrm{~nm})$, Bacillus subtilis at $(419 \mathrm{~nm})$, and Streptococcus thermophilus at $(420 \mathrm{~nm})$ are potential candidates for this purpose.

\section{Material and Methods}

2.1. Bacteria Used for Synthesis of Ag Nanoparticles. The test strains Escherichia coli ATCC 8739 and Bacillus subtilus ATCC 6633 were obtained from our culture collection (Bacteriology Unit at Botany Department, Faculty of Science, Tanta University) and cultivated in LB broth containing g/L Tryptone 10.0, Yeast extract 5.0, Sodium Chloride 10.0, $1000 \mathrm{~mL}$ distilled water according to [18]. Streptococcus thermophilus ESh1 was isolated from yoghurt and cultivated on ST broth containing g/L Casein enzymic hydrolysate 10.0, Yeast extract 5.0, Sucrose 10.0, Dipotassium phosphate 2.0, $1000 \mathrm{~mL}$ distilled water according to [19].

2.2. Preparation of Supernatants. Luria and Burrous broth, and ST broth were prepared, sterilized, and inoculated with a freshly grown inoculum of the test strains Escherichia coli ATCC 8739, Bacillus subtilus ATCC 6633, and Streptococcus thermophilus ESh1. The culture flasks were incubated for $24 \mathrm{~h}$ at $35^{\circ} \mathrm{C}$. After the incubation period, the cultures were centrifuged at $6000 \mathrm{rpm}$ and their supernatants were used for further experiments.

2.3. Synthesis of Silver Nanoparticles. Aqueous silver nitrate solution $\left(10^{-3} \mathrm{M}\right)$ was separately added to reaction vessels containing different supernatants $(1 \%, \mathrm{v} / \mathrm{v})$, and the resulting mixture was allowed to stand for $5 \mathrm{~min}$ at room temperature.

2.4. UV-Visible Spectroscopy. The reduction of the $\mathrm{Ag}^{+}$ions by the supernatant of the test bacteria in the solutions and formation of silver nanoparticles were characterized by UV-visible spectroscopy monitored by sampling the aqueous component $(2 \mathrm{~mL})$ and measuring the UV-Vis spectrum of solutions. The UV-Vis spectra of these samples were measured on a Cecil model 9200 Ultraviolet visible spectrophotometer operated at a resolution of $1 \mathrm{~nm}$.
2.5. Transmission Electron Microscopy (TEM). The silver nanoparticles formed by the culture supernatants of the test bacteria were used for transmission electron microscopy (TEM; Joel, 100SX, Japan with AMT digital camera). Each specimen was dispersed ultrasonically to separate individual particles, and one or two drops of the suspension was deposited onto holey-carbon coated copper grids and dried under infrared lamp. The silver nanoparticles film was observed and photographed by transmission after $72 \mathrm{~h}$ of incubation.

2.6. X-Ray Diffraction. The formation of silver nanoparticles was checked by X-ray diffraction (XRD) technique using an X-ray diffractometer (Phillips PW 1729/40 generator, diffractometer, one line reactor) with $\mathrm{Cu} K_{\alpha}$ radiation $\lambda=$ $1.5405 \AA$ over a wide range of Bragg angles as $\left(20-80^{\circ} \mathrm{C}\right)$. Glass slides coated with silver nanoparticles thin films were used. For more efficient loading, slides were coated with silica gel then loaded with silver nanoparticles solution.

2.7. Antimicrobial Activity. The test microorganisms Serratia marcescens W225, Bacillus subtilus, Escherichia coli, Staphylococcus aureus, Salmonella typhimurium, Klebsiella pneumoniae, Pseudomonas aeruginosa, and Candida albicans were obtained from the culture collection of Bacteriology Unit at Botany Department, Faculty of Science, Tanta University. Nutrient broth, sabouraud's broth, and nutrient agar were used for growing the test bacteria and the fungus like yeast (C. albicans). The antimicrobial spectrum of the synthesized Ag nanoparticles was determined by the cut plug method [20] on plates seeded with the tested bacteria and inoculum fungus. Overnight cultures of the bacterial and C. albicans indicators were prepared in nutrient and sabouraud broths and inoculums diluted to $1 \times 10^{5} \mathrm{cfu} / \mathrm{mL}$. For bacterial and fungal indicators, $200 \mu \mathrm{L}$ of $1 \times 10^{5} \mathrm{cfu} / \mathrm{mL}$ were stirred well in nutrient or sabouraud agar plates. After solidification, the wells of $5 \mathrm{~mm}$ diameters were made and each was filled with $100 \mu \mathrm{L}$ of the silver nanoparticles previously prepared by different bacterial strains under investigation. The plates were then incubated at $30^{\circ} \mathrm{C}$ for $24 \mathrm{hrs}$, after which the diameters of inhibition zones were measured to estimate its inhibitory effects.

\section{Results and Discussion}

There are several physical and chemical methods for synthesis of metallic nanoparticles that are followed [21]. However, development of simple and eco-friendly biological systems would help in the synthesis and application of metallic nanoparticles. Some microorganisms interact with metal ions reducing them into metallic nanoparticles $[6,9]$.

The formation of silver nanoparticles by the culture supernatants of Escherichia coli ATCC 8739, Bacillus subtilus ATCC 6633, and Streptococcus thermophilus ESh1 was carried out. The cell filtrate of the tested bacterial strains incubated with silver ion (1 mg) is represented in Figure 1. Rapid appearance of a yellowish-brown color in the reaction vessels suggested the formation of colloidal silver nanoparticles. 


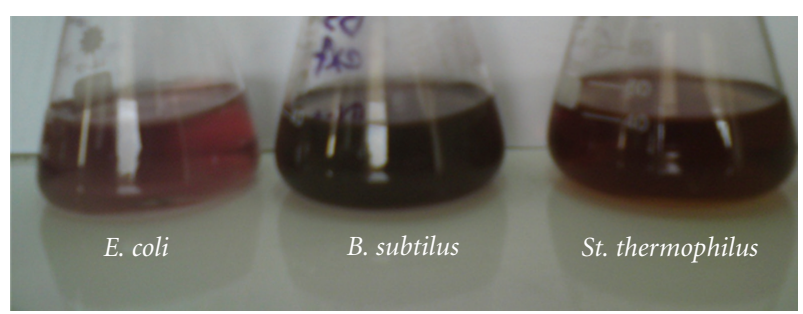

Figure 1: Solutions of silver nitrate after exposure to the culture supernatant of (from left to right) E. coli ATCC8739, B. subtilus ATCC6633, and St. thermophilus ESh1.

This may be due to the excitation of surface plasmon vibrations, typical of silver nanoparticles [5]. Figure 1 shows three conical flasks with the supernatants of E. coli ATCC 8739, B. subtilus ATCC 6633, and St. thermophilus ESh1 after reaction with $\mathrm{Ag}^{+}$for $5 \mathrm{~min}$. contact time with cell filtrate. In previous reports, [10] has shown extracellular synthesis of silver nanoparticles within hours of contact time with cell filtrate of Fusarium oxysporum [4]. The authors also reported that silver nanoparticles were formed within minutes upon contact with the cell filtrate of Aspergillus fumigatus. The synthetic process of silver nanoparticles was quite fast and silver nanoparticles were formed within 5 minutes of silver ion coming in contact with the cell filtrate of Enterobacteria [5]. Rapid extracellular synthesis shown by our tested bacteria is of great advantages over fungi and intracellular synthesis protocols since it avoids possible contamination with mycotoxins. Before reaction, the silver containing solution was colorless that changed to a brownish color upon completion of the reaction. The color noted by visual observation of the medium changed in intensity giving brown color after $24 \mathrm{~h}$ of incubation. This increase in intensity could be due to the formation of more nanoparticles. The solution remained in the hydrosol form, and no precipitation was observed even after $72 \mathrm{~h}$ of incubation. No changes in color of the cell filtrates were observed when the supernatants derived from control cultures without silver ions were incubated under the same conditions. This indicates that certain reducing agents released into the cultures of the tested bacteria are involved in the reduction of silver ions to silver nanoparticles. This evidence is supported by the study made by [5] using Enterobacteria. In this context, several hydrogenous intermediates were reported as electron shuttles in the process of metal reduction $[15,22]$.

The UV-Visible absorption spectra of the cell filtrates were measured in the range of $300-600 \mathrm{~nm}$ using a double beam UV-Visible spectrophotometer. Short-term incubation was carried out within few minutes of introducing silver ions into the flask containing cell filtrate resulting in an increase in absorbance in the spectral range of 350-600 nm, Figures 2(a), 2(b), and 2(c) for E. coli ATCC 8739, B. subtilus ATCC 6633, and St. thermophilus ESh1, respectively. The electronic absorption technique outlined above has proved to be very useful for the analysis of nanoparticles as illustrated by [23-25]. Figures 2(a), 2(b), and 2(c) show a strong broad absorption band located between 420 and $430 \mathrm{~nm}$ for silver nanoparticles prepared by the three tested microorganisms.
The fact that silver nanoparticles band remained around $420 \mathrm{~nm}$ indicates that the particles were well dispersed without aggregation. Observation of this band, assigned to a surface plasmon, is well documented for various metal nanoparticles with sizes ranging from 2 to $100 \mathrm{~nm}[24,26]$. The strong surface of plasmon resonance absorption of silver nanoparticles prepared using E. coli ATCC 8739, B. subtilus ATCC 6633 and $S_{t}$. thermophilus ESh1 was centered at ca. 430,419 , and $420 \mathrm{~nm}$, respectively. The absorbance in the range of 350-600 $\mathrm{nm}$ increases with increasing incubation time.

Further studies were carried out using X-ray diffraction to confirm the crystalline nature of silver nanoparticles. Figures 3(a), and 3(c) show the X-ray diffraction patterns of nanoparticles prepared using E. coli ATCC 8739, B. subtilus ATCC 6633, and St. thermophilus ESh1, respectively. Xray diffractograms of nanoparticles synthesized by different bacterial strains showed four intense peaks in the diffraction range of $2 \theta$ values from 20 to $80^{\circ}$. The nanoparticles present in the aqueous medium were quite stable at $25^{\circ} \mathrm{C}$. This is an important aspect of synthesis of nanoparticles, since the lack of sufficient stability of many nanoparticle preparations has, to some extent, impeded the development of the real world applications of nanomaterials. The four intense peaks observed in the diffractograms agree with the Braggs's reflections of silver nanocrystals reported in the literature [25]. This further confirms that the silver nanoparticles formed in the extracellular filtrate are present in the form of silver nanocrystals. In future, it would be important to understand the biochemical and molecular mechanism of the synthesis of the nanoparticles by the cell filtrate in order to achieve better control over size and polydispersity of the nanoparticles.

Figures 4(a), 4(b), and 4(c) show the TEM images of silver nanoparticles synthesized by using culture supernatants of E. coli ATCC 8739, B. subtilus ATCC 6633, and St. thermophilus ESh1, respectively. The particle size ranges in from 28 to $122 \mathrm{~nm}$ and possesses an average size of $52.5 \mathrm{~nm}$. In addition, the TEM images show at least two different areas, one with higher contrast due to silver nanoparticles and the other of lower contrast which is probably due to other micro(or even nano-) crystals originating from insoluble Ag salts. The majority of silver nanoparticles were in a dispersed form with only a few of them showing aggregates of varying sizes. The result obtained from TEM studies (Figure 4) gives a clear indication regarding the shape and size of the nanoparticles. As shown in the SEM images, the majority of nanoparticles was of spherical shape and appeared to be reasonably monodispersed. The sizes of the silver particles were found to be in the range of 5-25 nm diameters. Such variation in shape and size for nanoparticles synthesized by biological systems is commonly obtained. However, if the process of silver nanoparticles is to be a viable alternative to the current chemical method, then greater control over particle size and polydispersity would be required.

The antimicrobial activity of precipitated silver nanoparticles formed by different tested organisms showed different inhibitory effect on different human pathogenic bacteria Escherichia coli, Bacillus subtilus, Salmonella typhimurium, 


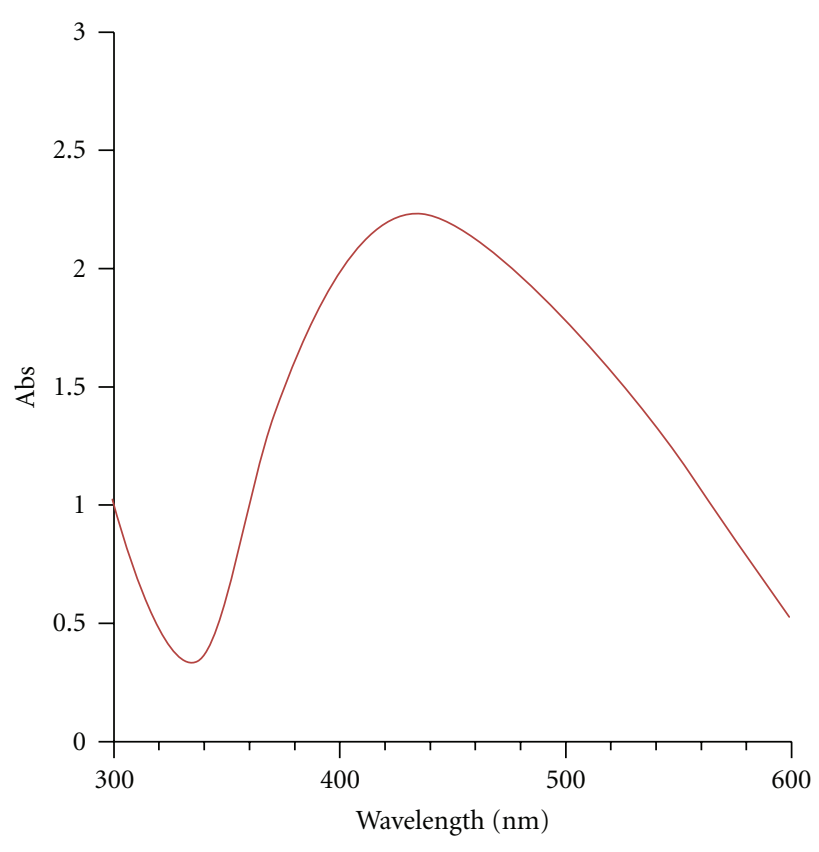

(a)

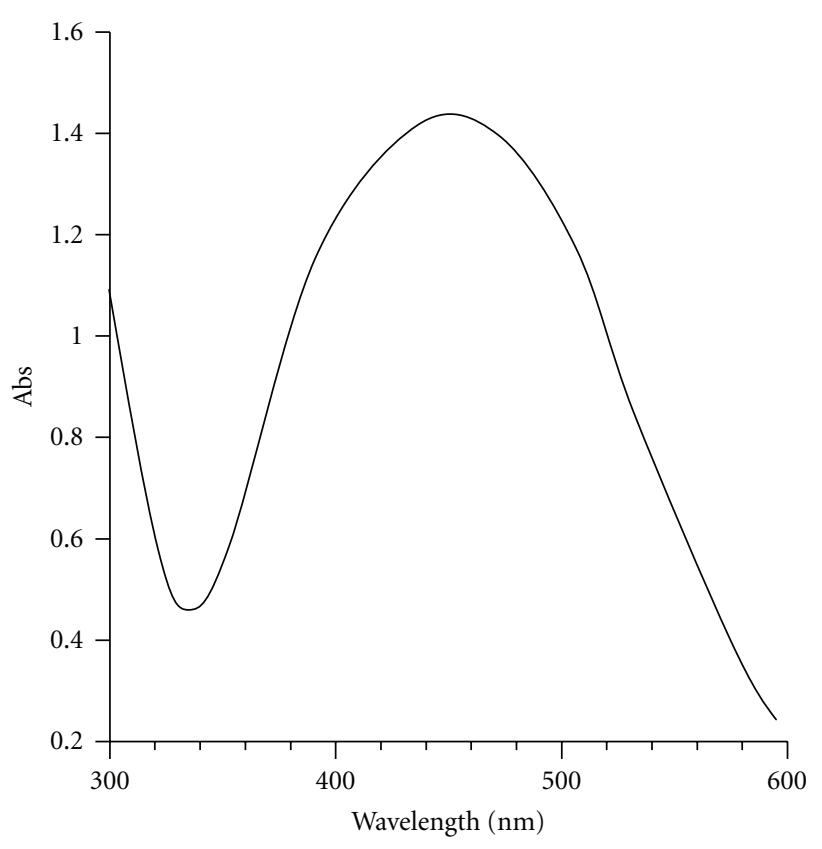

(b)

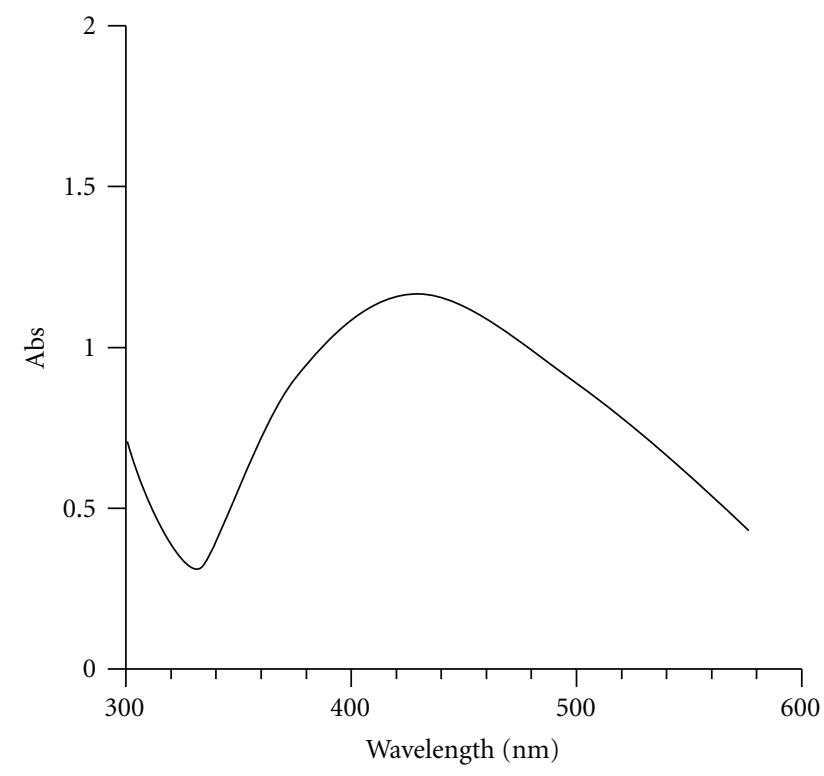

(c)

Figure 2: (a, b, and, c) show UV-Visible spectrum of silver nanoparticles produced by filtrate E. coli, B. subtilis, and St. thermophilus.

TABLE 1: Antimicrobial activity of the synthesized Ag nanoparticles on different microorganisms (inhibition zone).

\begin{tabular}{|c|c|c|c|}
\hline Tested organisms & E. coli Ag nanoparticles & B. subtilus Ag nanoparticles & St. thermophilus Ag nanoparticles \\
\hline E. coli & 6.3 & 5.5 & 5.5 \\
\hline B. subtilus & 9.7 & 5.2 & 4.8 \\
\hline S. typhumirum & 3.5 & 3.5 & 4.3 \\
\hline K. pneumonia & 4.6 & 2.6 & 3.7 \\
\hline St. aureus & 5.4 & 3.9 & 4.6 \\
\hline P. aeruginosa & 3.8 & 3.4 & 2.5 \\
\hline C. albicans & 5.0 & 6.8 & 4.4 \\
\hline
\end{tabular}




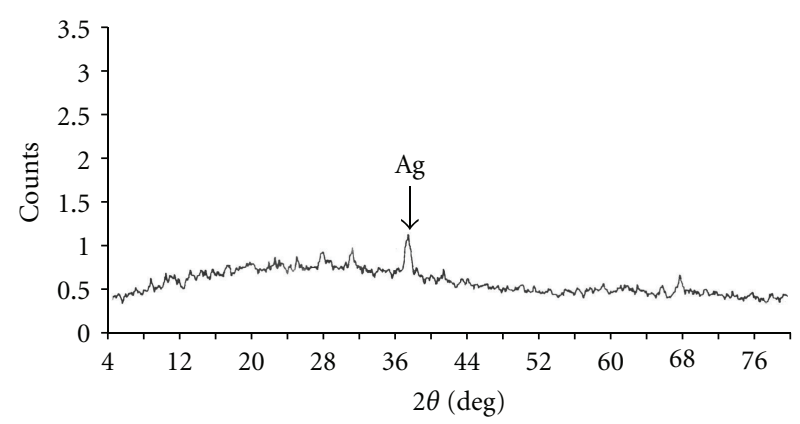

(a)

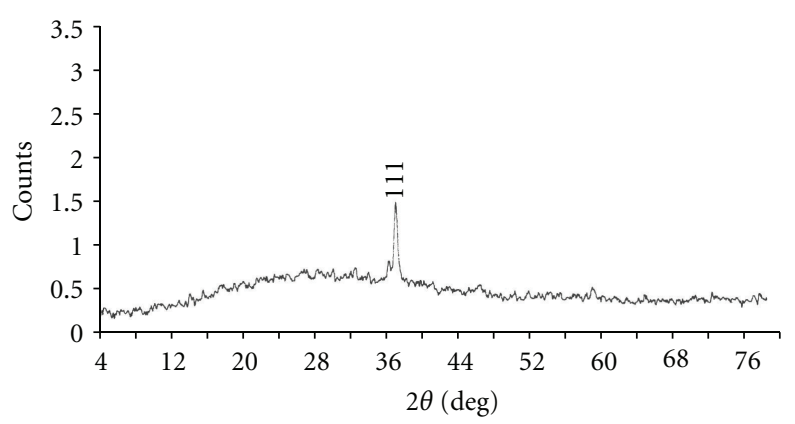

(b)

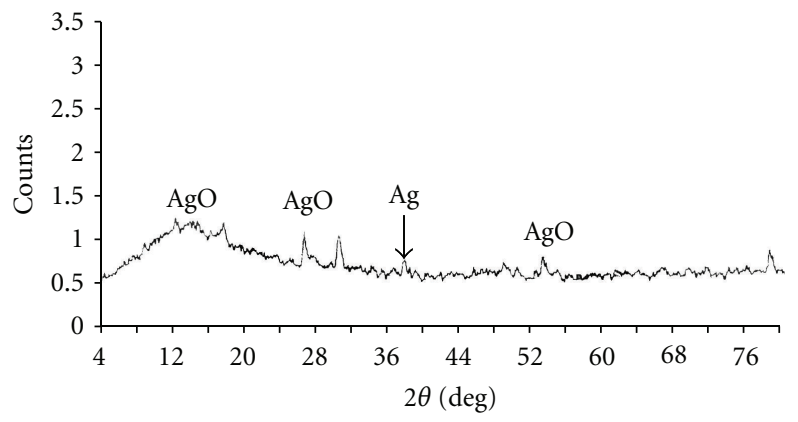

(c)

Figure 3: (a, b, and, c) show X-ray powder diffraction of silver nanoparticles produced by E. coli, B. subtilis and St. thermophilus, respectively.

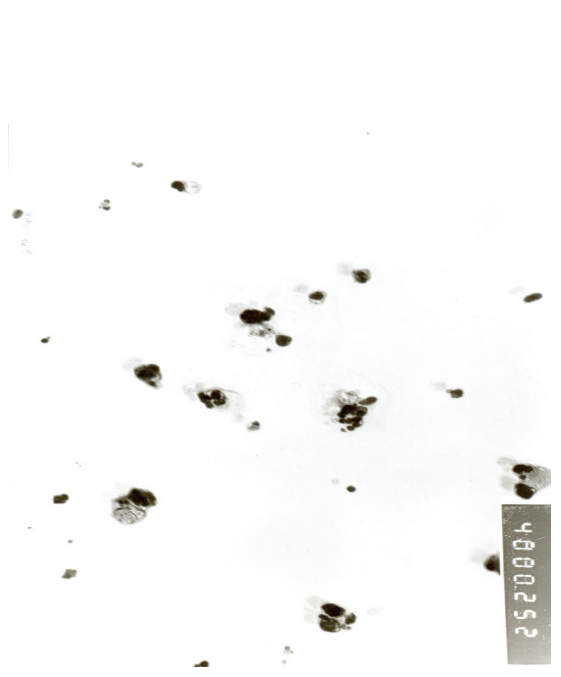

(a)

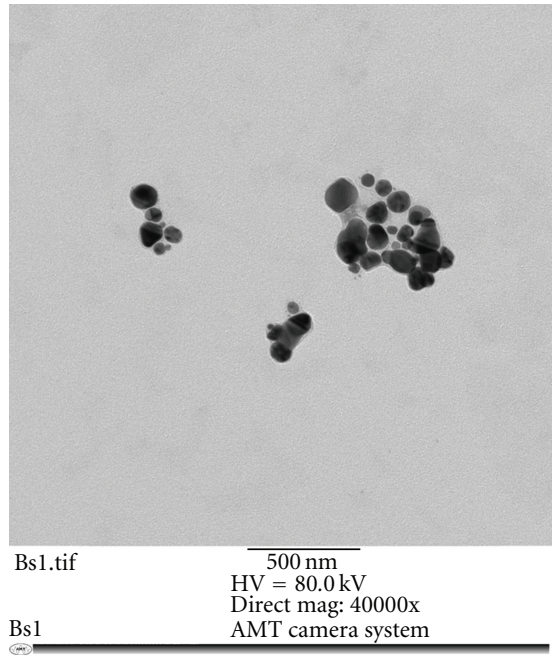

(b)

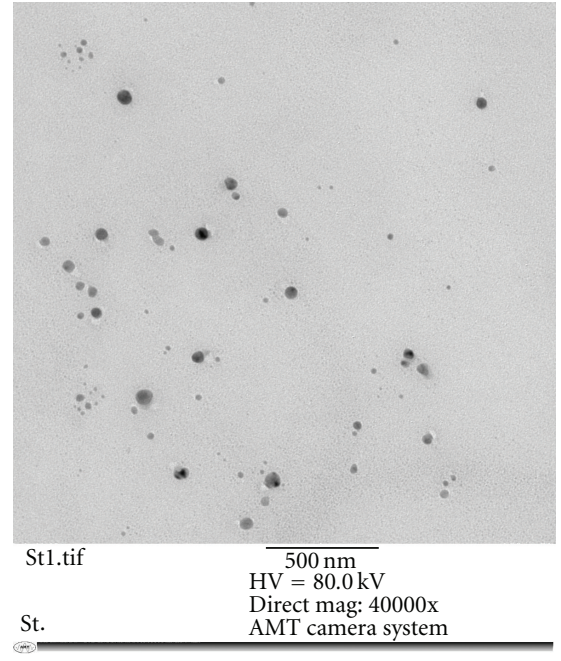

(c)

Figure 4: (a, b, and c) show TEM electron micrographs of silver nanoparticles produced by E. coli, B. subtilus and St. thermophilus, respectively.

Klebsiella pneumoniae, Staphlococcus aureus, and Pseudomonas aeruginosa and the fungus like yeast Candida albicans which showed different inhibition zone with different size. The results in Table 1 revealed that most of the precipitated silver nanoparticles showed antibacterial and antifungal activity with varying magnitudes. This dissimilarity might be due to different interactions of nanoparticles with the tested organisms. The mechanism of inhibitory action of silver ions on microorganisms is partially known. It is believed that DNA loses its replication ability and cellular proteins become inactivated upon $\mathrm{Ag}^{+}$treatment [27]. In addition, it was also shown that $\mathrm{Ag}^{+}$binds to functional groups of proteins, resulting in protein denaturation. [2830] showed when E. coli bacteria were treated with highly reactive metal oxide nanoparticles; a bacterial membrane exhibits a significant increase in permeability, leaving the bacterial cells incapable of properly regulating transport through the plasma membrane and ultimately causing cell 
death. Also [31] has shown that metal depletion may cause the formation of irregular-shaped pits in the outer membrane and changed membrane permeability. This is caused by progressive release of LPS molecules and membrane proteins.

\section{Acknowledgments}

The authors would like to express their gratitude to Dr. Elzeny M. Ebied Professor of physical chemistry and Head of Chemistry Department, Faculty of Science, Tanta University for his help and support of this work.

\section{References}

[1] T. J. Beveridge, M. N. Hughes, H. Lee et al., "Metalmicrobe interactions: contemporary approaches," Advances in Microbial Physiology, vol. 38, pp. 177-243, 1997.

[2] K. Simkiss and K. M. Wilbur, "Biomineralization," Cell Biology and Mineral Deposition, Academic. Press, New York, NY, USA, 1989.

[3] S. Mann and G. A. Ozin, "Synthesis of inorganic materials with complex form," Nature, vol. 382, no. 6589, pp. 313-318, 1996.

[4] K. C. Bhainsa and S. F. D'Souza, "Extracellular biosynthesis of silver nanoparticles using the fungus Aspergillus fumigatus," Colloids and Surfaces B, vol. 47, no. 2, pp. 160-164, 2006.

[5] A. R. Shahverdi, S. Minaeian, H. R. Shahverdi, H. Jamalifar, and A. A. Nohi, "Rapid synthesis of silver nanoparticles using culture supernatants of Enterobacteria: a novel biological approach," Process Biochemistry, vol. 42, no. 5, pp. 919-923, 2007.

[6] A. K. Jha and K. Prasad, "Biosynthesis of metal and oxide nanoparticles using Lactobacilli from yoghurt and probiotic spore tablets," Biotechnology Journal, vol. 5, no. 3, pp. 285-291, 2010.

[7] T. Klaus, R. Joerger, E. Olsson, and C. -G. Granqvist, "Silverbased crystalline nanoparticles, microbially fabricated," Proceedings of the National Academy of Sciences of the United States of America, vol. 96, no. 24, pp. 13611-13614, 1999.

[8] B. Nair and T. Pradeep, "Coalescence of nanoclusters and formation of submicron crystallites assisted by lactobacillus strains," Crystal Growth and Design, vol. 2, no. 4, pp. 293-298, 2002.

[9] T. Klaus-Joerger, R. Joerger, E. Olsson, and C. G. Granqvist, "Bacteria as workers in the living factory: metal-accumulating bacteria and their potential for materials science," Trends in Biotechnology, vol. 19, no. 1, pp. 15-20, 2001.

[10] A. Ahmad, S. Senapati, M. I. Khan, R. Kumar, and M. Sastry, "Extracellular biosynthesis of monodisperse gold nanoparticles by a novel extremophilic actinomycete, thermomonospora sp," Langmuir, vol. 19, no. 8, pp. 3550-3553, 2003.

[11] S. S. Shankar, A. Rai, A. Ahmad, and M. Sastry, "Rapid synthesis of $\mathrm{Au}, \mathrm{Ag}$, and bimetallic $\mathrm{Au}$ core-Ag shell nanoparticles using Neem (Azadirachta indica) leaf broth," Journal of Colloid and Interface Science, vol. 275, no. 2, pp. 496-502, 2004.

[12] M. Kowshik, N. Deshmukh, W. Vogel, J. Urban, S. K. Kulkarni, and K. M. Paknikar, "Microbial synthesis of semiconductor CdS nanoparticles, their characterization, and their use in the fabrication of an ideal diode," Biotechnology and Bioengineering, vol. 78, no. 5, pp. 583-588, 2002.
[13] G. I. H. Souza, P. D. Marcato, N. Duran, and E. Esposito, "Utilization of Fusarium oxysporum in the biosynthesis of silver nanoparticles and its antibacterial activities," in Proceedings of the 9th National Meeting of Environmental Microbiology, p. 25, 2004.

[14] G. Cao, Nanostructures and Nanomaterials: Synthesis, Properties and Applications, Imperial College Press, Hackensack, NJ, USA, 2004.

[15] N. Durán, P. D. Marcato, O. L. Alves, G. I. H. De Souza, and E. Esposito, "Mechanistic aspects of biosynthesis of silver nanoparticles by several Fusarium Oxysporum strains," Journal of Nanobiotechnology, vol. 3, article 8, 2005.

[16] M. R. Bruins, S. Kapil, and F. W. Oehme, "Microbial resistance to metals in the environment," Ecotoxicology and Environmental Safety, vol. 45, no. 3, pp. 198-207, 2000.

[17] T. J. Beveridge and R. G. E. Murray, "Sites of metal deposition in the cell wall of Bacillus subtilis," Journal of Bacteriology, vol. 141, no. 2, pp. 876-887, 1980.

[18] S. E. Luria and J. W. Burrous, "Hybridization between Escherichia coli and Shigella," Journal of Bacteriology, vol. 74, no. 4, pp. 461-476, 1957.

[19] S. Y. Lee, E. R. Vedamuthu, C. J. Washam, and G. W. Reinbold, "An agar medium for the differential enumeration of yogurt starter bacteria," . Journal of Milcrobial Food Technology, vol. 37, no. 5, pp. 272-276, 1974.

[20] T. G. Pridham, P. Anderson, C. Foley, L. A. Lindenfelser, C. W. Hessetine, and R. G. Benedict, "A selection of media for maintenance and taxonomic study of streptomycetes," Antibiotics Annual, pp. 947-953, 1956.

[21] A. S. Edelstein and R. C Cammarata, Eds., Nanomaterials: Synthesis, Properties and Applications, IOP Publication, Philadelphia, Pa, USA, 1996.

[22] R. A. Baker and J. H. Tatum, "Novel anthraquinones from stationary cultures of Fusarium oxysporum," Journal of Fermentation and Bioengineering, vol. 85, no. 4, pp. 359-361, 1998.

[23] A. Henglein, "Physicochemical properties of small metal particles in solution: "Microelectrode" reactions, chemisorption, composite metal particles, and the atom-to-metal transition," Journal of Physical Chemistry, vol. 97, no. 21, pp. 5457-5471, 1993.

[24] M. Sastry, V. Patil, and S. R. Sainkar, "Electrostatically controlled diffusion of carboxylic acid derivatized silver colloidal particles in thermally evaporated fatty amine films," Journal of Physical Chemistry B, vol. 102, no. 8, pp. 1404-1410, 1998.

[25] H. W. Lu, S. H. Liu, X. L. Wang, X. F. Qian, J. Yin, and Z. $\mathrm{K}$. Zhu, "Silver nanocrystals by hyperbranched polyurethaneassisted photochemical reduction of $\mathrm{Ag}^{+}$," Materials Chemistry and Physics, vol. 81, no. 1, pp. 104-107, 2003.

[26] M. Sastry, K. S. Mayya, and K. Bandyopadhyay, "pH Dependent changes in the optical properties of carboxylic acid derivatized silver colloidal particles," Colloids and Surfaces A, vol. 127, no. 1-3, pp. 221-228, 1997.

[27] Q. L. Feng, J. Wu, G. Q. Chen, F. Z. Cui, T. N. Kim, and J. O. Kim, "A mechanistic study of the antibacterial effect of silver ions on Escherichia coli and Staphylococcus aureus," Journal of Biomedical Materials Research, vol. 52, no. 4, pp. 662-668, 2000.

[28] I. Sondi and E. Matijević, "Homogeneous precipitation by enzyme-catalyzed reactions. 2. Strontium and barium carbonates," Chemistry of Materials, vol. 15, no. 6, pp. 1322-1326, 2003.

[29] I. Sondi and B. Salopek-Sondi, "Silver nanoparticles as antimicrobial agent: a case study on E. coli as a model for 
Gram-negative bacteria," Journal of Colloid and Interface Science, vol. 275, no. 1, pp. 177-182, 2004.

[30] P. K. Stoimenov, R. L. Klinger, G. L. Marchin, and K. J. Klabunde, "Metal oxide nanoparticles as bactericidal agents," Langmuir, vol. 18, no. 17, pp. 6679-6686, 2002.

[31] N. A. Amro, L. P. Kotra, K. Wadu-Mesthrige, A. Bulychev, S. Mobashery, and G. Y. Liu, "High-resolution atomic force microscopy studies of the Escherichia coli outer membrane: structural basis for permeability," Langmuir, vol. 16, no. 6, pp. 2789-2796, 2000. 

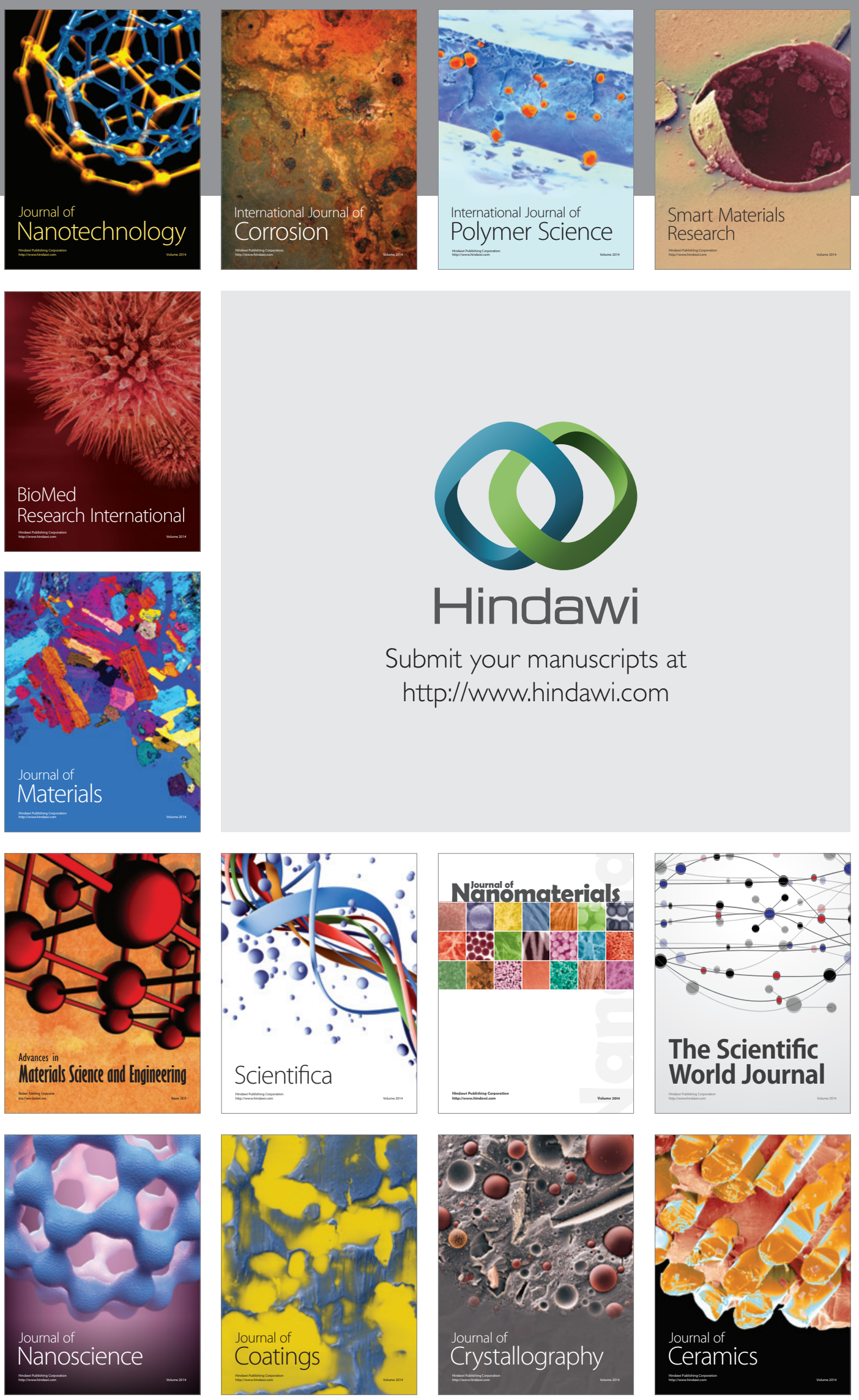

The Scientific World Journal

Submit your manuscripts at

http://www.hindawi.com

\section{World Journal}

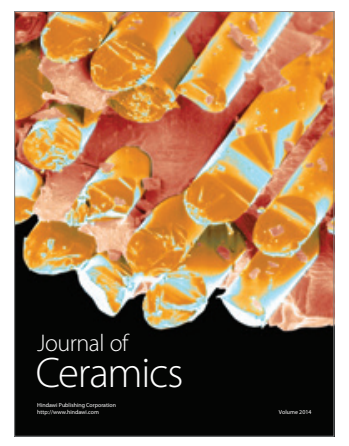

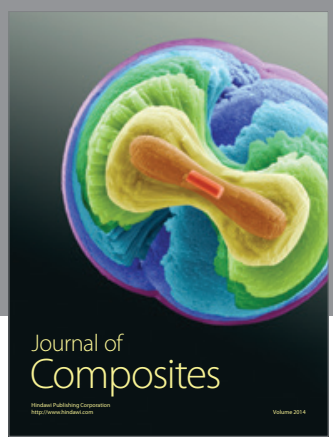
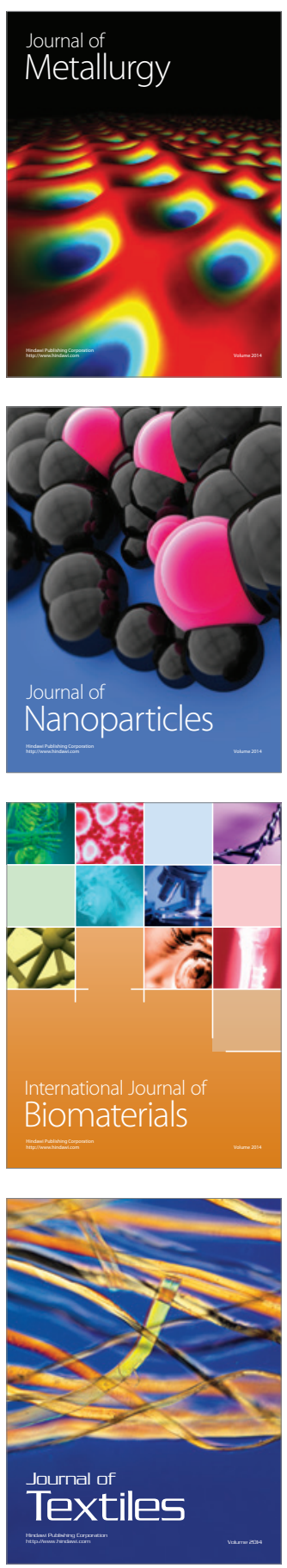